\title{
Design Thinking in Nursing Education to Improve Care for Lesbian, Gay, Bisexual, Transgender, Queer, Intersex and Two-Spirit People
}

\author{
Erin Ziegler, NP-PHC, PhD (1) \\ Benjamin Carroll, RN, MNSc (i) \\ Chris Shortall, MSc (1)
}

\begin{abstract}
Design thinking methodology is a collaborative strategy with the potential to create innovations. Design thinking is being used increasingly in health care. Design jams are interdisciplinary events that bring together experts and community members to collaborate on creative solutions to health-care problems. This article describes the design thinking process and includes reflection on the authors' participation in a design jam event aimed to address the knowledge-to-action gap that exists in health care for (LGBTQI2S) people.
\end{abstract}

Keywords: design thinking; knowledge transfer; LGBTQI/Two-Spirit (LGBTQI2S); nurses; education; design jam

$\mathrm{D}$ esign thinking methodology is a framework to foster creative and interdisciplinary approaches to innovations. The aim is to develop effective solutions to current problems using creative thinking and a human-centered approach (Eines \& Vatne, 2017). Successful implementation of design thinking in health care can improve clinical practice, quality of care, and patient outcomes (Rahemi, D'Avolio, Dunphy, \& Rivera, 2018). This methodology was used to address a knowledge-to-action gap in health care for lesbian, gay, bisexual, transgender, queer, intersex and TwoSpirit (LGBTQI2S) people. This article presents the authors' experience at a design jam hosted by the Canadian Institutes of Health Research (CIHR) to design a tool for knowledge transfer and exchange (KTE) in nursing education. This article aims to describe design thinking, critique our experience, and highlight implications for creative development of nursing tools.

\section{PROBLEM DESCRIPTION}

Historically, research about health care for gender minorities has focused on LGBT people, with a dearth of literature about barriers to care for queer, intersex, and Two-Spirit people. LGBT people experience distinct health disparities and are one of the largest underserved populations in health care (Eliason, Dibble, \& Dejoseph, 2010; Institute of Medicine, 2011). Barriers contributing to health disparities include discrimination, lack of provider experience and knowledge, and a deficiency of services (Institute of Medicine, 2011). Lack of knowledgeable health-care providers has been identified as a key barrier to culturally sensitive health care for the LGBT population (Grant et al., 2010; Sanchez, Sanchez, \& Danoff, 2009).

Content about caring for LGBTQI2S people is lacking in baccalaureate nursing curricula, with a median time of 2.12 hours devoted to the topic in U.S. nursing programs (Lim, Johnson, \& Eliason, 2015). Similarly, programs in Canada provided limited, inconsistent, non-standardized content in LGBTQI2S health and wellness (Shortall, 2019). Rondahl (2009) explored nursing students' understanding of the LGBT population and found that their knowledge was inadequate, with only $10 \%$ of students achieving a passing mark on a LGBT knowledge questionnaire. Faculty who feel unprepared to teach LGBTQI2S content have been identified as a major barrier for including it in nursing curricula (Eliason et al., 2010; Shortall, 2019). Recommendations have been made regarding key content for curricula to provide a strong foundation for cultural 
humility with LGBTQI2S patients (Kelley, Chou, Dibble, \& Roberston, 2008; Safer \& Pearce, 2013; Strong \& Folse, 2015; Walsh Brennan, Barnsteiner, De Leon Siantz, Cotter, \& Everett, 2012), yet there is no evidence that these recommendations have been implemented in nursing curricula. Providing nurses with a better understanding of LGBTQI2S health issues and inequalities would reduce barriers faced by this population when accessing health care (Mayer et al., 2008).

The CIHR Institute of Gender and Health, in conjunction with Hacking Health, a volunteer-run organization that hosts design thinking events, created a 2-day KTE development initiative based on the theme of Innovative Thinking to Support LGBTQI2S Health and Wellness (CIHR, 2019). Trainee awards funded the authors and other graduate students and researchers from across Canada to attend this event. We were teamed with local health-care providers, LGBTQI2S community members, and marketing experts to develop campaigns, services, or products to disseminate research evidence to improve health outcomes (Michael Smith Foundation for Health Research, 2018).

\section{DESIGN JAM PROCESS}

The format of this event was a design jam, a modality within design thinking methodology very similar to a hackathon. Design thinking involves five steps:

1. Empathize: Consider the population experiencing the health challenge.

2. Define: Focus on the specific problem.

3. Ideate: Brainstorm a large quantity and broad diversity of ideas in rapid sessions.

4. Prototype: Develop and plan potential solutions.

5. Test: Ask experts and end users for feedback on prototypes to refine and develop the KTE product. (Canadian Institutes of Health Research, 2018; Institute for Design at Stanford, 2010).

Within the design thinking process, design jams are a modality created by the computer science and technology industries (Institute for Design at Stanford, 2010). In a design jam, a focused problem is framed by the organizers and sponsors, and a solution product is developed by interdisciplinary teams (To, 2016). Hackathons, similar technology-focused events, include a competitive element (Kos, 2019; To, 2016). The design jam we attended included prizes that supported project development, but the competition was not the main focus. Our design jam team consisted of two graduate nursing students (BC, EZ), a graduate student in health policy (CS), a facilitator from a major LGBTQI2S advocacy group, and a graphic artist.

\section{Empathizing and Defining}

The design jam started with an orientation to design thinking and LGBTQI2S health. Defining the problem more clearly was informed by the orientation, our expertise in LGBTQI2S health, and communication with the LGBTQI2S community members present. Our group decided that creating a product for nurses to increase knowledge and skill in providing positive and safe care to LGBTQI2S patients would address the knowledge-to-action gap for LGBTQI2S care.

\section{Ideating and Prototyping}

Brainstorming activities facilitated the description of the population (nurses) who would use our product, what they would need and want, and possible means by which we could impart the necessary knowledge. Our group envisioned the diversity of nurses who might engage with a KTE product to learn more about providing safe care to the LGBTQI2S population. We designed an online educational tool kit with learning objectives, curated resources, virtual simulation games, self-assessments, and reflection opportunities. We pitched this product to the judges and stakeholders at the end of the design jam.

\section{Testing}

We tested our prototype on other health-care participants at the design jam. We engaged with members of the LGBTQI2S community represented in the product plan to ensure that the format and content were accurate.

Recommendations have been
made regarding key content for
curricula to provide a strong
foundation for cultural humility
with LGBTQI2S patients, yet
there is no evidence that these
recommendations have been
implemented in nursing curricula.




\section{The graphic artist admitted that she was drawing on popular television drama representations of nurses in her descriptions of young, stylish, energetic feminine nurses who were working in obstetrics or pediatrics, single, and dating heterosexually.}

\section{Ongoing Project Development}

Following the 2-day design jam, the authors partnered with academic nurse researchers specializing in developing virtual simulation games for nurses to continue the development of the project. A detailed description of the development process is discussed in a separate manuscript (Luctkar-Flude et al., 2019). The goal of the project is to advance nurses' cultural humility in caring for LGBTQI2S people. The objectives of the tool kit are:

- To describe nurse's knowledge and attitudes regarding sexuality and gender diversity

- To explore personal values and biases

- To describe the unique health issues experienced by LGBTQI2S people

- To adapt assessment techniques and develop skills for working with LGBTQI2S people

The tool kit consists of four case-based scenarios and four rapid-fire scenarios (see Table 1). After each scenario the learner is presented with strategies for debriefing and self-reflective questions.

In order to allow for continual professional development, the tool kit also included curated resources that can be used in practice (a selection of key resources is available in Table 2).

\section{Critique of the Design Jam Process}

Our team reflected on the facilitators and barriers contained in the design jam process. Our experience did confer a number of facilitators and benefits common to design jams and hackathons: informal learning and practice in collaboration, communication, delegation, fast-paced and time-sensitive project management, pitching, and teamwork, as well as networking opportunities (Kos, 2019). All of the teams at the design jam produced workable outputs in the form of a knowledge translation product prototype and a plan for development (To, 2016). The event was well run, including a welcoming environment, play and growth opportunities for the participants that embraced a beginner's view of design thinking and creative products, non-intimidating project development, and use of prize incentives (Kos, 2019).

\section{Author reflection on participation:}

It was a good networking opportunity to meet other people working diligently to identify and address issues surrounding LGBTQI2S health and wellness and healthcare provision issues . . . I found it a great way to get empowered in the esoteric area of LGBTQI2S health promotion, and hugely beneficial to learn and know that good things are happening across Canada [and] to develop a way to improve LGBTQI2S educational content in nursing. (CS)

Part of the design process involves envisioning the typical end user of the product. Our experience was that the qualities and characteristics we were asked to describe risked stereotyping health providers. Relying on stereotypes would also risk creating products that did not fit the reality of the target audience.

Author reflection on participation:

The exercise was to fully imagine the end user. Describe them in rich detail: their age, what they looked like, their job, friends, car, hobbies, family. We had decided that our end user was a nurse. It was notable to me how the depictions reflected many nursing stereotypes. The graphic artist admitted that she was drawing on popular television drama representations of nurses in her descriptions of young, stylish, energetic feminine nurses who were working in obstetrics or pediatrics, single, and dating heterosexually. (BC)

The research and testing phases of the process relied on a small number of community members local to the event, in a major Canadian city with a well-developed LGBTQI2S community and a strong health and social services net. The experiences of community members there would not necessarily translate across Canada. Considerations for LGBTQI2S people in smaller cities and rural and remote areas should be considered. Similarly, there were few middle-aged, elderly, or Two-Spirit community members. 


\begin{tabular}{|c|c|}
\hline Topic & Key Issues Addressed \\
\hline $\begin{array}{l}\text { Case 1: Older gay male seeing health-care provider related } \\
\text { to grief following the loss of his partner. }\end{array}$ & $\begin{array}{l}\text { Communication-Coming out to provider } \\
\text { Heterosexism } \\
\text { Avoiding stereotypes }\end{array}$ \\
\hline Case 2: Transgender youth with anxiety. & $\begin{array}{l}\text { Unsupportive parents } \\
\text { Creating safe space } \\
\text { Identifying community resources }\end{array}$ \\
\hline $\begin{array}{l}\text { Case 3: Queer young female presenting for annual physical } \\
\text { exam. }\end{array}$ & $\begin{array}{l}\text { Not making assumptions } \\
\text { Heterosexism } \\
\text { Asking good questions } \\
\text { Obtaining a sexual health history including risk for } \\
\quad \text { pregnancy }\end{array}$ \\
\hline $\begin{array}{l}\text { Case } 4 \text { : Transgender male presenting for health care for a } \\
\text { problem not related to his gender. }\end{array}$ & $\begin{array}{l}\text { Legal and social transition } \\
\text { Understanding language of transgender person }\end{array}$ \\
\hline $\begin{array}{l}\text { Rapid-Fire 1: Transgender person in clinic. Preferred name } \\
\text { not used. }\end{array}$ & Using preferred names and pronouns \\
\hline Rapid-Fire 2: Ill child with two female parents. & Not making assumptions \\
\hline $\begin{array}{l}\text { Rapid-Fire 3: Inappropriate disclosure of a patient's sexual } \\
\text { orientation by a health-care practitioner. }\end{array}$ & $\begin{array}{l}\text { Stigma } \\
\text { Confidentiality }\end{array}$ \\
\hline Rapid-Fire 4: Patient presenting for STI testing. & $\begin{array}{l}\text { Creating a safe space } \\
\text { Not making assumptions }\end{array}$ \\
\hline
\end{tabular}

Note. STI = sexually transmitted infection. Adapted from Luctkar-Flude et al. (2019)

TABLE 2. Curated LGBTQI2S Resources

\begin{tabular}{ll}
\hline \multicolumn{1}{c}{ Resource } & \multicolumn{1}{c}{ Website } \\
\hline $\begin{array}{l}\text { An Introduction to the Health of Two-Spirit People: Historical, } \\
\text { Contemporary and Emergent Issues (Hunt, 2016) }\end{array}$ & $\begin{array}{l}\text { https://www.nccih.ca/454/An_Introduction_ } \\
\text { to_the_Health_of_Two-Spirit_People.nccah } \\
\text { https://apsc-saravyc.sites.olt.ubc.ca/files/2019/ } \\
\text { 08/SARAVYC_LGBTQ-Students-in-ON_Fact-Sheet- } \\
\text { LGBTQ+ Students in Ontario: 12 Evidence-Based Facts (Stigma } \\
\text { and Resilience Among Vulnerable Youth Centre, 2019) }\end{array}$ \\
$\begin{array}{l}\text { Infographic_FINAL.pdf } \\
\text { huidelines for Gender-Affirming Primary Care with Trans and } \\
\text { Non-Binary Patients (Bournes, 2020) }\end{array}$ & $\begin{array}{l}\text { trans-care/ } \\
\text { https://www.cpha.ca/sites/default/files/uploads/ } \\
\text { resources/stbbi/language-tool-e.pdf }\end{array}$ \\
$\begin{array}{l}\text { Sexual Health, Substance Use, STBBIs and Intersecting Sources } \\
\text { of Stigma (Canadian Public Health Association, 2019) }\end{array}$ & $\begin{array}{l}\text { https://www.canada.ca/en/employment-social- } \\
\text { development/corporate/seniors/forum/social- }\end{array}$ \\
$\begin{array}{l}\text { Social Isolation of Seniors: A Focus on LGBTQ Seniors in Canada-for- } \\
\text { (Employment \& Social Development Canada, 2019) }\end{array}$ & $\begin{array}{l}\text { isolation-lgbtq.html } \\
\text { https://fenwayhealth.org/care/medical/transgender- } \\
\text { health/ }\end{array}$ \\
\hline $\begin{array}{l}\text { Transgender Health (Fenway Health, 2020) } \\
\end{array}$
\end{tabular}

Author reflection on participation:

The research portion was informed by a group of local community members. As we needed to talk to anyone, an announcement with the particulars of the community members sought was made: "Any trans men or women who transitioned as youth please go to table 5 for research." Many of the announcements were repeated as it became obvious that there were no community or researcher participants that fit the description being requested. (BC) 


\section{Design thinking innovations involving community collaborations may be more acceptable and effective compared to more expert-driven methods.}

A series of scaffolded design thinking events could focus attention on various processes in knowledge translation product development (To, 2016): focused networking events such as unconferences (Budd et al., 2015) for fulsome community engagement, design jam engagement for solution ideation, and finally a hackathon for product prototyping, then testing by community members. As this process occurs over a longer time period, reflection and adjustments can be made to correct oversights. Follow-up support on product development, project management, and dissemination is a step seen as crucial by design thinking experts (To, 2016).

Author reflection on participation:

It was a whirlwind experience. Fast paced with not a lot of time to process or reflect on the decisions being made. The event was held over two very long days. It was a challenge to learn about the design thinking process, develop a protocol, and present a sales pitch to "sell" our proposed product in less than 48 hours. Although we got it all done, it would have been better if it was not condensed into the short timeframe. (EZ)

\section{IMPLICATIONS AND USE OF DESIGN THINKING IN NURSING}

Health care requires innovations that are appropriate, evidence based, and that represent creative and imaginative solutions to problems (MacFadyen, 2014). Design thinking allows nurses to creatively develop solutions to improve practice as well as creative KTE products. Design thinking innovations involving community collaborations may be more acceptable and effective compared to more expert-driven methods (Altman, Huang, \& Breland, 2018). Device designing, improving interventions and patients' experiences, teaching, and developing community health programs have all been implemented in health care using design thinking (Hendricks, Conrad, Douglas, \& Mutsvangwa, 2018).

\section{CONCLUSION}

Design thinking methodology has potential to develop innovative and creative products for nursing practice and education. This article explored our experience at a design thinking event to address the knowledge-to-action gap in health care for LGBTQI2S people. Through the design jam process, we were able to create an online education tool kit (in process, www.soginursing.ca) that aims to provide nurses with the knowledge and skills to provide safe, quality care for LGBTQI2S people.

\section{REFERENCES}

Altman, M., Huang, T. T. K., \& Breland, J. Y. (2018). Design thinking in health care. Preventing Chronic Disease, 15(117), 1-13. http:/ /dx.doi.org/10.5888/pcd15.180128

Bournes, A. (2020). Guidelines for gender-affirming primary care with trans and non-binary patients. Retrieved from https://www.rainbowhealthontario.ca/wp-con tent/uploads / / woocommerce_uploads/2019/12/Guid elines-FINAL-Dec-2019.pdf

Budd, A., Dinkel, H., Corpas, M., Fuller, J. C., Rubinat, L., Devos, D. P., \& Wood, N. T. (2015). Ten simple rules for organizing an unconference. PLOS Computational Biology, 11(2), 1-8. http://dx.doi.org/ 10.1371/journal.pcbi.1003905

Canadian Institutes of Health Research. (2018). Hacking the knowledge gap in health research. Retrieved from https: / / cihr-irsc.gc.ca/e/49872.html

Canadian Institutes of Health Research. (2019). Hacking the knowledge gap trainee award for innovative thinking to support LGBTQI2S health and wellness (2017/18). Retrieved from http:/ / cihr-irsc.gc.ca/e/50531.html

Canadian Public Health Association.(2019). Language matters: Using respectful language in relation to sexual health, substance use, STBBIs and intersecting sources of stigma. Retrieved from https://www.cpha.ca/sites/default/files/uploads/res ources/stbbi/language-tool-e.pdf

Eines, T. F., \& Vatne, S. (2017). Nurses and nurse assistants' experiences with using a design thinking approach to innovation in a nursing home. Journal of Nursing Management, 26, 425-431. http:/ /dx.doi.org/10.1111/jonm.12559

Eliason, M. J., Dibble, S., \& Dejoseph, J. (2010). Nursing's silence on lesbian, gay, bisexual, and transgender issues: The need for emancipatory efforts. Advances in Nursing Science, 33(3), 206-218. http:/ /dx.doi.org/10.1097/ANS.0b013e3181e63e49

Employment and Social Development Canada(2019). Social isolation of seniors: A focus on LGBTQ seniors in Canada. Retrieved from https://www.canada. 
ca/en/employment-social-development/corporate/ seniors/forum/social-isolation-lgbtq.html

Fenway Health(2020). Transgender health. Retrieved from https:/ / fenwayhealth.org/care/medical/transgenderhealth/

Grant, J., Mottet, L., Tanis, J., Harrison, J., Herman, J., \& Keisling, M. (2010). National transgender discrimination survery report on health and health care. Washington, DC: National Center for Transgender Equality and National Gay and Lesbian Task Force.

Hendricks, S., Conrad, N., Douglas, T., \& Mutsvangwa, T. (2018). A modified stakeholder participation assessment framework for design thinking in health innovation. Healthcare, 6, 191-196. http://dx.doi.org/ 10.1016/j.hjdsi.2018.06.003

Hunt, S. (2016). An introduction to the health of TwoSpirit people: Historical, contemporary and emergent issues. Prince George, BC: National Collaborating Centre for Aboriginal Health. Retrieved from https://www.nccih.ca/454/An_Introduction_to_the_ Health_of_Two-Spirit_People.nccah

Institute for Design at Stanford. (2010). An introduction to design thinking process guide. Retrieved from https://ds chool-old.stanford.edu/sandbox/groups/designresou rces/wiki/36873/attachments/74b3d/ModeGuideBO OTCAMP2010L.pdf

Institute of Medicine. (2011). The health of lesbian, gay, bisexual, and transgender people: Building a foundation for better understanding. Washington, DC: National Academies Press.

Kelley, L., Chou, C., Dibble, S., \& Roberston, P. (2008). A critical intervention in lesbian, gay, bisexual, and transgender health: Knowledge and attitude outcomes among second-year medical students. Teaching and Learning in Medicine, 20(3), 248-253. http:/ /dx.doi.org/10.1080/10401330802199567

Kos, B. A. (2019). An autoethnography of T9 hacks: Designing a welcoming hackathon for women and non-binary students to learn and explore computing. Doctoral dissertation, University of Colorado at Boulder. ProQuest Dissertations and Theses database. (UMI No. 13860744).

Lim, F., Johnson, M., \& Eliason, M. (2015). A national survey of faculty knowledge, experience, and readiness for teaching lesbian, gay, bisexual, and transgender health in baccalaureate nursing programs. Nursing Education Perspectives. Nursing Education Perspectives, 36 (3) 144-152. https:/ / doi.org/10.5480/14-1355

Luctkar-Flude, M., Tyerman, J., Ziegler, E., Carroll, B., Shortall, C., Chumbley, L. \& Tregunno, D. (2019). Developing a sexual orientation and gender identity nursing education toolkit. Manuscript submitted for publication.

MacFadyen, J. S. (2014). Design thinking. Holistic Nursing Practice, 28(1), 3-5. http://dx.doi.org/ 10.1097/HNP.00000000000000008

Mayer, K., Bradford, J., Makadon, H., Stall, R., Goldhammer, H., \& Landers, S. (2008). Sexual and gender minority health: What we know and what needs to be done. American Journal of Public Health, 98(6), 989-995. https:/ / doi.org/10.2105/AJPH.2007.127811

Michael Smith Foundation for Health Research. (2018). LGBTQI2S community members wanted to bridge research and care gap. Retrieved from https://www.msfhr.org/n ews/msfhr-news/LGBTQI2S-research-care

Rahemi, Z., D'Avolio, D., Dunphy, L., \& Rivera, A. (2018). Shifting management in healthcare: An interative review of design thinking. Nursing Management, 49(12) 30-37. http://dx.doi.org/ 10.1097/01.NUMA.0000547834.95083.e9

Rondahl, G. (2009). Students' inadequate knowledge about lesbian, gay, bisexual and transgender persons. International Journal of Nursing Education Scholarship, 6(1), 1-15. https:/ / doi.org/10.2202/1548-923X.1718

Safer, J. D., \& Pearce, E. (2013). A simple curriculum content change increased medical students comfort with transgender medicine. Endocrine Practice, 19(4), 633-637. http://dx.doi.org/10.4158/EP13014.OR

Sanchez, N. F., Sanchez, J. P., \& Danoff, A. (2009). Health care utilization, barriers to care, and hormone usage among male-to-female transgender persons in New York City. American Journal of Public Health, 99(4), 713-719. http:/ /dx.doi.org/10.2105/AJPH.2007.132035

Shortall, C. (2019). Teaching and evaluation/assessment requirements for LGBTQI2S+ health and wellness: A call to include LGBTQI2S+ content in Canadian English baccalaureate nursing curricula. Quality Advancement in Nursing Education, 5(1), 1-17. https:/ / doi.org/10.17483/2368-6669.1169

Stigma and Resilience Among Vulnerable Youth Centre(2019). LGBTQ+ students in Ontario: 12 Evidence-based facts. Retrieved from http://apsc-sar avyc.sites.olt.ubc.ca/files/2019/08/SARAVYC_LGBTQStudents-in-ON_Fact-Sheet-Infographic_FINAL.pdf

Strong, K., \& Folse, V. (2015). Assessing undergraduate nursing students' knowledge, attitudes, and cultural competence in care for lesbian, gay, bisexual, and transgender patients. Journal of Nursing Education, 54(1), 45-49. https:/ / doi.org/10.3928/01484834-20141224-07

To, J. (2016). Understanding the potential of public engagement: Hackathons and jams. (Masters thesis). OCAD University of Toronto. Retrieved from http:/ / openresearch.ocadu.ca/id/eprint/666/database

Walsh Brennan, A., Barnsteiner, J., De Leon Siantz, M., Cotter, V., \& Everett, J. (2012). Lesbian, gay, bisexual, transgendered, or intersexed content for nursing curricula. Journal of Professional Nursing, 28(2), 96-104. http://dx.doi.org/10.1016/j.pronurs.2011.11.004

Disclosure. The authors have no relevant financial interest or affiliations with any commercial interests related to the subjects discussed within this article.

Funding. The authors received funding from the CIHR Institute of Gender and Health to support the attendance at the Design Jam event and the development of the educational tool.

Correspondence regarding this article should be directed to Erin Ziegler at eziegler@ryerson.ca 


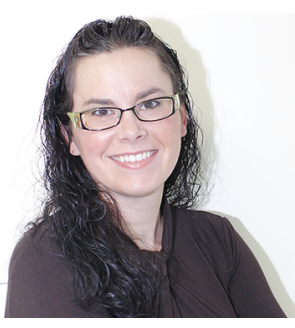

Erin Ziegler, NP-PHC, PhD (she/her/ hers), is an assistant professor with the Daphne Cockwell School of Nursing at Ryerson University in Toronto, Ontario, and a primary health-care nurse practitioner.

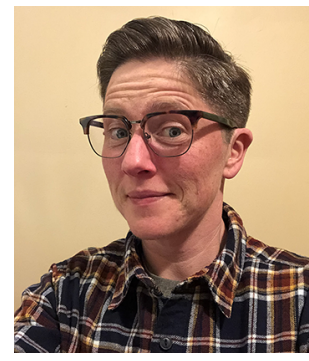

Benjamin Carroll, RN, MNSc (he/him/ his), is a PhD student and teaching fellow at Queen's University in Kingston, Ontario.

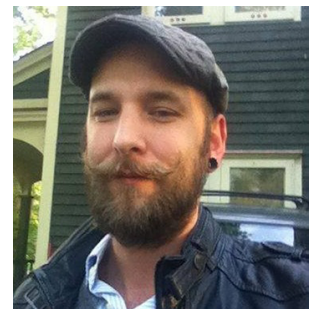

Chris Shortall, MSc (they/them/their), is the director of Rainbow Health Consulting Ltd. In Newfoundland. 